\title{
Structural Behavior of Long Span Overhead Sign Support Bridges
}

\author{
Ishtiaque Ahmed Tuhin \\ infraTECH Engineers and Innovators, LLC, Houston, Texas, USA \\ Email: ishtiaque.tuhin16@gmail.com
}

How to cite this paper: Tuhin, I.A. (2020) Structural Behavior of Long Span Overhead Sign Support Bridges. Open Journal of Civil Engineering, 10, 1-8.

https://doi.org/10.4236/ojce.2020.101001

Received: December 22, 2019

Accepted: January 11, 2020

Published: January 14, 2020

Copyright $\odot 2020$ by author(s) and Scientific Research Publishing Inc. This work is licensed under the Creative Commons Attribution International License (CC BY 4.0).

http://creativecommons.org/licenses/by/4.0/

\begin{abstract}
Overhead sign-support bridges that allow displaying necessary information for travelers across the multiple lanes in highways often use large message sign panels: static message sign (SMS) panels or dynamic message sign (DMS) panels. Along with conventional SMS panel, the use of DMS panel is increasing in highways over time owing to their effective capability to guide the travelers in real-time. A $230-\mathrm{ft}$ long span 4-chord overhead steel truss bridge attached with SMS and DMS panel has been studied through extensive finite element analysis to observe the structural integrity. The static wind load was applied in model truss for four different configurations as per 2016 AASHTO LRFD design specification. The innovative structural detailing approach for truss end support and connection detailing for toll-equipment supporting frame was proposed based on static analysis. The present study will help engineers to design overhead sign support bridges by ensuring both public safety and structural integrity.
\end{abstract}

\section{Keywords}

Sign-Support Bridge, Static Message Sign (SMS), Dynamic Message Sign (DMS), Finite Element Analysis, Wind Load

\section{Introduction}

The large highway support signs are used on freeways, expressways, and major arterials for better management of traffic flow by providing accurate and timely information to travelers that can be classified as static message sign (SMS) and dynamic message sign (DMS). DMS is used to control, warn, and inform drivers during their travel without interrupting the traffic. To avoid any danger for drivers associated with intermediate supports on median or any other locations, the length of sign support structures is usually greater to the adjacent roadway 
[1]. The highway sign structures are always considered as flexible because of their long span length and relatively small cross-sectional area and mass. Due to the flexibility, their damping ratio is usually low, which can be $1 \%$ of critical damping. The underdamped property makes sign structures susceptible to large-amplitude vibration which may damage the structures due to fatigue under repetitive wind loads [2]. The number of lanes is increasing day by day in highways/expressways in all major cities in the USA because of increasing traffic volume [3]. Those locations need special attention to provide accurate and timely guidelines for travelers including imminent hazards. DMS panel is essential for this type of services but it may create torsional impacts on support truss connection [3].

Several studies [3]-[10] on both experimental and analytical have been carried out to evaluate the structural behavior of sign support structures. Most of the studies are discussed in detail for cantilever support structures and tubular truss members. Limited studies have been conducted to observe the behavior of four-chord truss. None of the studies was carried out with full-cover of SMS only or a combination of SMS and DMS for four-chord truss support bridges, constructed with steel angles. From past studies, it can be summarized that fatigue cracking is very critical for sign-support structures especially carrying DMS cabinet and sudden failure is not new.

The wind forces are very crucial for overhead sign support bridges because of the size, span length, and adjacent sign panel. The detailed knowledge of the wind forces acting on overhead sign support bridge members and adjacent sign panels are deemed necessary to predict an accurate behavior of such structures, especially when attached with DMS panel. The public safety is crucial in highways for such long span overhead sign support bridges. A 230-ft long span 4-chord overhead steel truss bridge attached with SMS and DMS panel has been studied through extensive finite element analysis to observe the structural integrity. The general structural behavior of model truss bridge was examined by applying static wind loads for four different configurations: (I) truss only (reference model), (II) truss without physical attachment of sign SMS or DMS panel, (III) truss with physical attachment of SMS panel, and (IV) truss with both SMS and DMS panel. The goal of this research is to investigate wind and thermal effects on overhead trusses supporting with SMS and DMS and understand the behavior causing cracks in truss members. However, only the effect of static wind loads along with dead load and live load is present in this study.

\section{Research Motivation, Significance, and Future Contributions}

After ages of infrastructures, highway structures pose a major problem and sometimes it is tough to remedy this problem due to limited timeframe or financial resources. Therefore, knowledge about critical members of four-chord overhead sign support structures can be useful for state highway agencies in near 
future. This type of research can assist them effectively that needs to be inspected closely, repaired or replaced. Most of the Department of Transportation (DOT) divisions in USA have their design specifications and construction drawings for sign support bridges. However, many of them are not revised based on recent AASHTO LRFD design specifications. There is also lack of proper design guideline for connection detailing between supporting frame for sign panel (or supporting frame for toll-equipment, lighting etc.) and primary truss members. As per Author knowledge, no one has specific design instruction beyond 200-ft span with a full cover of SMS or DMS cabinet based on current AASHTO LRFD design specifications.

The goal of this study is to provide design guideline for long-span overhead sign bridges, where designers will have the flexibility for using of SMS or DMS panel or both. Both static and dynamic analysis will be performed through extensive finite element analysis. New innovative approach "impact of road profile" will be applied in this model truss. This extensive research works can be categorized as: Task 1-Structural integrity of long span overhead sign support structures following current code specifications; Task 2-Artificial wind gust under extreme weather condition through CFD analysis; Task 3-Fatigue behavior because of natural wind gust pressure along with truck induced pressure, galloping, and vortex shedding; Task 4-Thermal expansion, diurnal temperature change, and damage during transportation; Task 5-Heavy truck induced load and impact of road profile. This model structure will be analyzed for all possible hazards that will help to eliminate catastrophic damages of truss during severe weather conditions. This innovative research work will contribute as a great aid along with the DOTs existing design guideline for overhead sign support bridges.

\section{Finite Element Modeling}

The finite element analysis software SAP2000 was used to develop a full-scale three-dimensional model for this model truss bridge. Figure 1 shows the typical elevation view of proposed model structure. Body constraints technique was applied in such a way that the truss along with the sign panel worked as a single structure to move together as one three-dimensional object. Body constraints were applied to connect SMS panel as shell element to vertical sign support beam to the truss. Stiffeners were used to reduce its flexibility so that the global modal behavior of the structure can be evaluated by performing modal analysis. In a similar way, DMS panel was also attached to the truss by applying body constraints technique. However, stiffeners were not considered for DMS panel as this was modeled as a solid shell element and will not compromise the global behavior of shape. Figure 2 shows the detail information of truss members and their properties.

Three types of load: dead loads, live loads, and wind loads were applied in the model truss. The dead loads consist of the members' self-weight along with the 


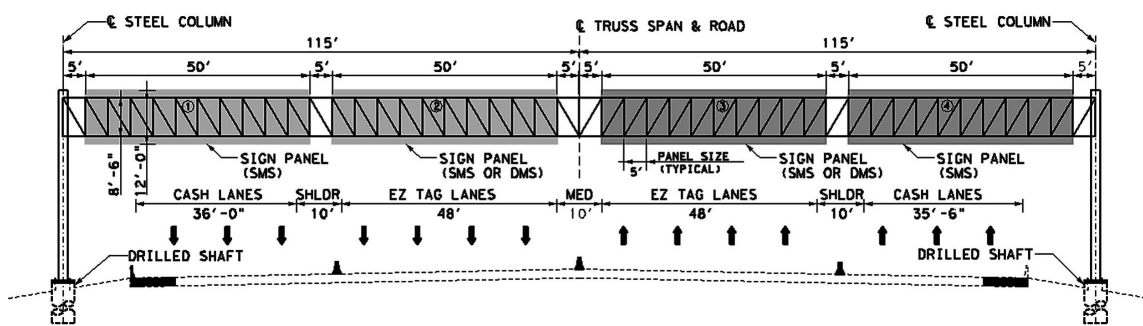

Figure 1. Elevation view of model truss bridge.

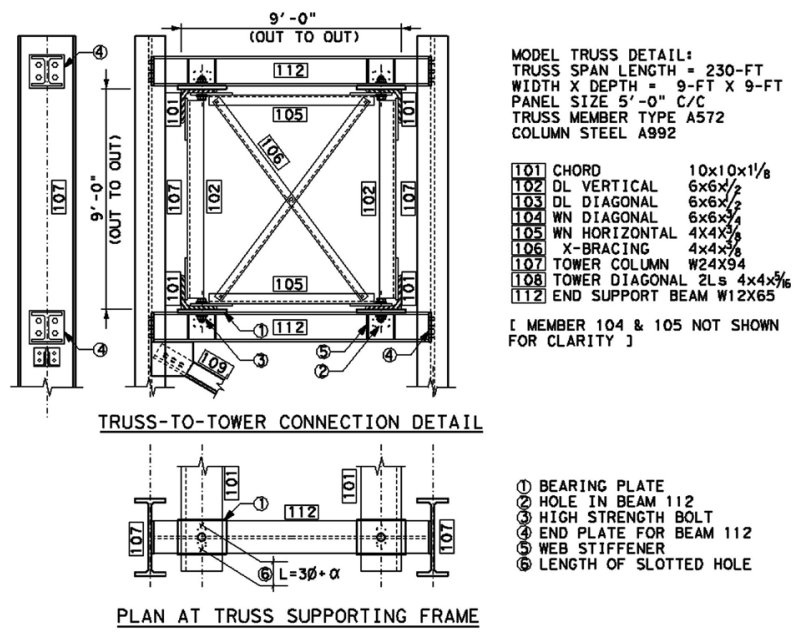

Figure 2. Typical section of model truss bridge.

attachment of sign components and additional dead load due to light and tolling equipment. Additional catwalk frame structure was not added in model truss because of the depth of the structure. However, the imposed load due to catwalk was added in the model as live loads. The static wind loads were calculated separately for sign panels and exposed truss frame elements as per AASHTO LRD 2016 [11] design specification and were incorporated into the model truss. Fatigue life and failure analysis are investigated for dynamic loads: Natural wind gust, heavy truck induced load, impact of road profile, diurnal temperatures during transportation. Lastly, the analysis results are verified with previous experimental studies. Only the effect of static wind loads along with dead load and live load is present herein.

\section{Preliminary Static Analysis Result and Discussion}

In order to verify that the model was built properly, hand calculation by following approximate equivalent beam method was performed at the center of the model truss, only self-weight of the truss members was applied to calculate the deflection. The equivalent beam method shows a deflection of 5.85-in while the base model truss gave a 5.33 in deflection which confirms the accuracy of the initial model set up. The overall deflection for service I load combination was evaluated from model truss and the value was in the limit $(\mathrm{L} / 150$, where $\mathrm{L}$ is the span length) as per AASHTO LRFD 2016 design specification [11]. The dynamic 
characteristics of structure, such as natural frequencies and modal shapes, are influenced by the support stiffness. The study Ginal [12] validated the result of the modal analysis using a single degree of freedom (SDOF) analogies and suggested that the support condition has little influence on dynamic behavior. Therefore, "fixed" supports were used for the base foundation in this analytical model. However, "pinned" conditions were applied at the end of truss end support (Figure 2). Figure 3 shows 3D view of model truss bridge for different configurations.

Table 1 shows the demand capacity ratio (R) of all primary truss members for all four model configurations. Since the goal was to observe overall structural behavior, specific truss members are not considered for this present study. The demand capacity ratios were selected based on extreme load cases. From the demand capacity ratio of the four models, it can be seen that $\mathrm{WN}$ diagonal and WN horizontal members had an influence when the truss model analyzed with the physical attachment of the sign panel. Though the applied wind pressure was same for all cases, the behavior of truss members was different because of attachment of sign panel.

In most of the cases, trusses collapse because of the connection failure, not for the failure of truss members. It is important to mention that truss with angles allows bolted connection between members and may also need welded connection in some cases which may impact the fatigue life of truss. The proper evaluations of fatigue life and damage assessments are necessary to minimize the catastrophic failure or damage caused by natural disasters. Some of the points can be summarized based on the static analysis of the model structure:

- Diagonal bracings are necessary at each panel point, reverse alternately. Cross-bracing is required at the adjacent panel point of chord splice location, at the end of the truss panel point, and on both sides of the middle panel joint for the stability of the truss frame.

- Welding or bolting connection between the vertical support member of sign panel (or toll equipment) and truss chord are not allowed as this type of connection will have an adverse impact on the fatigue behavior of the truss frame. The alternate connection shall be applied to avoid this situation. Figure 4 shows the proposed connection detail for toll-equipment.

- Thermal behavior might have an impact on the truss chord's actual length, which will compromise the structural integrity of the truss frame. Long slotted hole is necessary at the end of the truss end support to minimize the thermal impact of the truss frame. Figure 2 shows the arrangement of slotted hole at the truss end support.

- It is important to make tower truss as a rigid frame to resist horizontal force completely by tower truss and avoid uneven deflection tolerance in the main truss frame.

- The base of the tower truss shall be designed as a fully fixed connection, where special attention is needed for designing of the base plate and anchor bolts. 


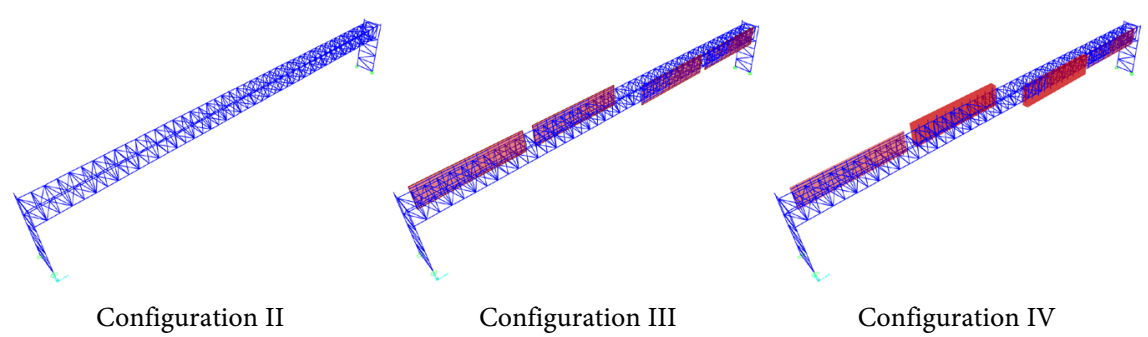

Figure 3. 3D view of model truss bridge with different configurations.
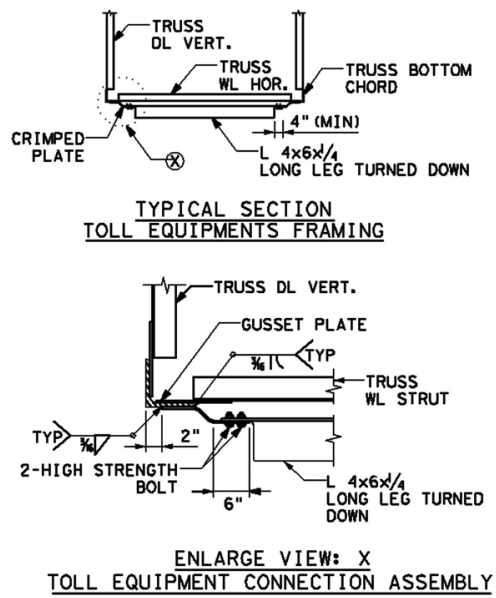

Figure 4. Connection detail for toll-equipment.

Table 1. Demand capacity ratio (R) of truss members for different model configurations.

\begin{tabular}{ccccc}
\hline Model Configuration & (I) & (II) & (III) & (IV) \\
\hline Member & $\mathrm{R}$ & $\mathrm{R}$ & $\mathrm{R}$ & $\mathrm{R}$ \\
Chord (101) & 0.650 & 0.649 & 0.924 & 0.931 \\
DL Vertical (102) & 0.573 & 0.564 & 0.418 & 0.421 \\
DL Diagonal (103) & 0.441 & 0.418 & 0.592 & 0.596 \\
WN Diagonal (104) & 0.229 & 0.404 & 0.691 & 0.695 \\
WN Horizontal (105) & 0.087 & 0.123 & 0.791 & 0.983 \\
\hline
\end{tabular}

\section{Conclusion}

The goal of this study was to observe the structural behavior of long-span overhead sign support bridges by applying static wind load based on the current AASHTO LRD design specifications. From preliminary analysis, it can be concluded that design engineers should analyze overhead sign support truss bridges with physical attachment of sign panel rather than wind load applied in adjacent frame members. The proper truss end support detailing is also necessary to avoid sudden failure of long-span overhead sign support trusses. However, the suggested design guidelines were prepared based on static analysis only. This analysis result may vary in severe weather condition, i.e. natural wind gust. It will be verified in the next phase of research through fatigue life and damaged assessment analysis for all possible load conditions such as natural wind gust 
and impact of road profile.

\section{Acknowledgements}

The author is thankful to infraTECH Engineers and Innovators, LLC to continue this innovative research works on "Long Span Overhead Sign Support Bridges" along with his regular professional design works.

\section{Conflicts of Interest}

The author declares no conflicts of interest regarding the publication of this paper.

\section{References}

[1] Kozy, B. and Earls, C.J. (2005) Bearing Capacity in Long-Span Tubular Truss Chord. ASCE Journal of Structural Engineering, 133, 356-367. https://doi.org/10.1061/(ASCE)0733-9445(2007)133:3(356)

[2] Li, X., Whalen, T.M. and Bowman, M.D. (2005) Fatigue Strength and Evaluation of Double Mast Arm Cantilevered Sign Structures. Transportation Research Record, 1928, 64-72. https://doi.org/10.1177/0361198105192800107

[3] Arabi, S., Shafei, B. and Phares, B.M. (2019) Investigation of Fatigue in Steel Sign-Support Structures under Diurnal Temperature Changes. Journal of Constructional Steel Research, 153, 286-297. https://doi.org/10.1016/j.jcsr.2018.09.024

[4] Arabi, S., Shafei, B. and Phares, B.M. (2018) Fatigue Analysis of Sign-Support Structures during Transportation under Road-Induced Excitations. Engineering Structures, 164, 305-315. https://doi.org/10.1016/j.engstruct.2018.02.031

[5] Alduse, B.P., Jung, S., Vanli, O.A. and Kwon, S.D. (2015) Effect of Uncertainties in Wind Speed and Direction on the Fatigue Damage of Long-Span Bridges. Engineering Structures, 100, 468-478. https://doi.org/10.1016/j.engstruct.2015.06.031

[6] Chang, B., Phares, B.M., Zou, H. and Couch, T. (2014) Thermal Analysis of Highway Overhead Support Structures. Transportation Research Record, 2406, 32-41. https://doi.org/10.3141/2406-04

[7] Hosch, I.E., Fouad, F.H., Gallow, M. and Traylor, L. (2017) Operational Post Deformation of Cantilever Sign Support Structures from Truck-Induced Wind Gusts. Practice Periodical on Structural Design and Construction, 23, 04017033. https://doi.org/10.1061/(ASCE)SC.1943-5576.0000352

[8] Hong, H.P., Zu, G.G. and King, J.P.C. (2016) Estimating Fatigue Design Load for Overhead Steel Sign Support Structures under Truck-Induced Wind Pressure. Canadian Journal of Civil Engineering, 43, 279-286. https://doi.org/10.1139/cjce-2015-0158

[9] Hosch, I.E. and Fouad, F.H. (2009) Fatigue Design of Sign Support Structures for Loading Caused by Natural Wind Loads. Transportation Research Record, 2131, 15-22. https://doi.org/10.3141/2131-02

[10] Kacin, J., Rizzo, P. and Tajari, M. (2010) Fatigue Analysis of Overhead Sign Support Structures. Engineering Structures, 32, 1659-1670.

https://doi.org/10.1016/j.engstruct.2010.02.014

[11] AASHTO LRFD (2016) LRFD Specifications for Structural Supports for Highway Signs, Luminaries, and Traffic Signals. American Association of State Highway and 
Transportation Officials (AASHTO), Washington, DC.

[12] Ginal, S. (2003) Fatigue Performance of Full-Span Sign Support Structures Considering Truck-Induced Gust and Natural Wind Pressures. MS Thesis, Marquette University, Milwaukee, Wisconsin. 